\title{
ENERGY CONSUMPTION BY SOLAR-POWERED WATERCRAFT AT VARIOUS SPEED SETTINGS
}

Dainis Berjoza, Inara Jurgena, Vitalijs Osadcuks

Latvia University of Life Sciences and Technologies, Latvia

dainis.berjoza@1lu.lv, inara.jurgena@1lu.lv,vtl@tvnet.lv

\begin{abstract}
Since the world's energy resources decrease, it is necessary to seek for opportunities to use renewable energy sources. One of the renewable sources is solar energy. During the last decade, solar energy was used by stationary installations for electricity generation, yet the use of solar energy by mobile installations is limited due to the size of solar photovoltaic panels. Modern vehicles typically use low-power solar panels to charge their batteries and power low-power electric devices. The present research used a plastic hull boat equipped with a standard electric motor Minn Kota Endura 30 and a 330W $36 \mathrm{~V}$ photovoltaic panel. Two experiments were conducted on the boat. During the pilot experiment, a distance of $41.5 \mathrm{~km}$ was covered by the boat equipped with a 5 Ah battery and a solar panel in 8.5 hours. The experiment was conducted on the Lielupe River upstream and downstream, seeking to reach the highest speed at different solar intensities in the month of August. The second experiment was conducted in September on a circular route in standing water, operating the boat at 5 different speed settings with average motor current consumption ranging from 7.3 to $21.86 \mathrm{~A}$. The experiment identified the battery's charging and discharging current and voltage, and the motor's current and voltage at all the speed settings. The experiments showed that on a sunny day in the conditions in Latvia, the boat equipped with a stationary 330W solar photovoltaic panel can reach a maximum speed of up to $6 \mathrm{kmh}^{-1}$ without using the battery. The efficiency of the solar panel was significantly affected by the direction of the boat's movement, which affected the angle of solar radiation and therefore the efficiency of the solar panel. To improve the efficiency of the solar panel, it is necessary to design a solar panel angle adjustment device that should be controlled automatically. Such a device is planned to be developed at the next stages of the research.
\end{abstract}

Keywords: electric boat, solar panel, speed setting, current, voltage.

\section{Introduction}

Modern vehicles tend to use alternative energy sources. One kind of alternative energy is electricity. The use of electric automobiles increases fast in European countries. In the period 2016-2019, the total number of electric automobiles in the EU increased from $1.1 \%$ to $3.0 \%$, while the total number of alternative energy-powered vehicles, which includes hybrid automobiles and those powered by LPG, natural gas and ethanol increased from $4.2 \%$ to $10.6 \%$ [1]. This trend is due to the support provided across countries for the use of automobiles powered by other energy sources, as well as the desire of the population to use newer, more environment-friendly technologies. Electric automobiles can make a significant contribution to reducing urban pollution, as the environmental impact could be reduced and transferred to the site of energy, in this case electricity, generation. However, the environmental impact of electric automobiles varies greatly, depending on the way electricity is produced, i.e. from renewable sources, e.g., wind, solar, hydropower, or it is electricity from nuclear and coal-fired thermal power plants. Mobile equipment, such as road electric vehicles and electric watercraft, make it quite difficult to fully use solar and wind energy to power their electric motors. Solar energy can usually provide only a small part of the energy needed for vehicle movement.

Although several prototypes of solar-powered automobiles have been developed and are called "solar vehicles" by their manufacturers, such vehicles are usually not capable of running solely on solar energy. In addition, the exploitation of such vehicles running on solar energy is highly dependent on the latitude of the location on the Earth, the time of the year and the time of the day. The intensity of solar radiation increases closer to the equator, as well at noon, while in the morning and evening it decreases significantly [2].

Various experiments are carried out on fully solar energy-powered vehicles, in which electric mobility scooters demonstrated an unlimited driving range in sunny weather [3], as well as races are held both on land and on water [4]. The idea of solar boats dates back to 1990 in the USA, yet the first boat race held for students took place in Japan in 1992. In those years, racing boats used solar panels with a power output of up to $480 \mathrm{~W}$ and batteries with a capacity of up to $1000 \mathrm{Wh}$. The average electrical power distribution between batteries and solar panels was designed to be 1:1 [5]. 
Racing boats are designed with a motor voltage of up to $52 \mathrm{~V}$ for a sprint distance of $5 \mathrm{~km}$ as well as a long distance that could reach $56 \mathrm{~km}$. The long distance requires a capacity of up to $1.2 \mathrm{~kW}$, while the sprint distance up to $5 \mathrm{~kW}$. Data monitoring is done during boat races, which allows boat performance parameters to be improved, e.g., the propeller design. Relevant research studies give main equations for calculating electrical circuits for a racing boat. The maximum solar panel power output of a racing boat can reach $5 \mathrm{~kW}$, while the speed of the boat can reach $25 \mathrm{~km} \cdot \mathrm{h}^{-1}$. After optimizing the propeller design, an average efficiency increase is $15 \%$, which allows a $175 \mathrm{~kg}$ boat to reach the same speed with lower energy consumption [6].

Taiwanese scientists have performed optimization of a solar boat, which was divided into two stages: the optimization of the boat design and the optimization of the boat's electrical controls and electrical drive. The scientists compared the structures of two boats having solar panel power outputs of $3.12 \mathrm{~kW}$ and $8.96 \mathrm{~kW}$. The structural solutions of the boats were as follows: displacements of 15.5 and $16.3 \mathrm{t}$ and length waterlines of $13.89 \mathrm{~m}$ and $14.44 \mathrm{~m}$, respectively [4].

As modern design solar-powered boats are built with underwater wings, their stability needs to be examined in order to achieve higher speeds. A mathematical model for identifying main parameters of the boat has been developed and research on boat stability has been done in the speed range from 6 to $15 \mathrm{~m} \cdot \mathrm{s}^{-1}$ [7]. Some scientists have divided the introduction of a solar-powered boat into several stages: concept development, mathematical model development, hydrodynamic analysis and prototype production. An optimal shape of boat hull has been developed according to the mathematical model [8].

Researchers at the University of the Amazon have performed an analysis of a solar boat with a daily mileage of less than $25 \mathrm{~km}$. The boat's waterline was $3.5 \mathrm{~m}$, while the total length was 4.5 meters. The area of solar panels was $7 \mathrm{~m}^{2}$, the boat was equipped with a $2.5 \mathrm{~kW}$ motor, which allowed to reach a speed of $7.4 \mathrm{~km} \cdot \mathrm{h}^{-1}$. The maximum energy efficiency of the boat was achieved at a low speed $[9 ; 10]$.

Serbian scientists have conducted solar boat research in various microclimatic conditions. Their experiment compared two solar panels placed at 15 and 5 degrees to the horizontal. The experiment recorded ambient and air temperatures. It was estimated that the boat's solar panels could annually generate an amount of energy equivalent to $174 \mathrm{l}$ of diesel, which made a significant economic effect [11]. A hybrid system could be used to propel alternative energy-powered boats, e.g., a combination of a diesel motor and an electric drive [12]. Applying complex mathematical models, it is possible to analyse and compare solar boats having different maximum speeds and hull parameters in detail [13].

Indian scientists have researched a solar boat equipped with 6 solar panels with a maximum voltage of $36 \mathrm{~V}$ and a power output of $300 \mathrm{~W}$. The solar panels were connected in series. The scientists developed a mathematical model to examine the boost converter. The equipment simulated provided an output voltage of $234 \mathrm{~V}$ and an output current of $3.94 \mathrm{~A}[14 ; 15]$.

German researchers have designed a solar boat Korona. The boat was equipped with 10 batteries, and the operating parameters of each battery shown on the display were logged. The data logger recorded data on the boat's speed, air and water temperatures, the motor's speed, voltage and current, the battery and the solar panel voltages and currents. The most important data were displayed on the control panel, yet all the data were transmitted to a stationary data collection facility onshore. The boat was equipped with a three-phase asynchronous motor [16].

Indonesian scientists have equipped a fishing boat with a solar-wind hybrid power system. Their research logged the energy generated by the system, depending on the intensity of solar radiation [17]. Research has been done also on solar-powered boats with a $0.6 \mathrm{~m}$ long boat hull, a $10 \mathrm{~W}$ solar panel and a $12 \mathrm{~V}$ motor [18].

A $12.64 \mathrm{~m}$ long cruise solar-powered boat has been developed in Indonesia. The boat can reach a cruise speed of $8 \mathrm{~km} \cdot \mathrm{h}^{-1}$, the total electric power consumed by the boat is $5.51 \mathrm{~kW}$. The solar boat was equipped with $58140 \mathrm{~W}$ solar panels. Research on the boat identified PV power outputs in different weather conditions: foggy, rainy, cloudy and sunny. A maximum energy output of $24.38 \mathrm{kWh}$ was produced on a sunny day, yet on a rainy day it was only $1.95 \mathrm{kWh}$ [19].

Standard boats are also converted into solar-powered boats, for example, a ferry boat in Bangladesh [20]. Solar-powered boats are convenient to transport tourists over short distances. The boat's operation is quiet and emission-free, while achieving an economic effect. Such a boat can travel at a speed of $15 \mathrm{~km} \cdot \mathrm{h}^{-1}$, its length is $14 \mathrm{~m}$ and width $5.5 \mathrm{~m}$. The research paper provides an analysis and calculations 
of all the systems. The boat is equipped with two electric motors, the onboard current can reach $44 \mathrm{~A}$, the total area of its solar panels is $55 \mathrm{~m}^{2}$ [21].

Exploiting a solar boat can significantly reduce emissions compared with traditional internal combustion engine boats. Polish scientists have performed a mathematical simulation for a boat equipped with a $1000 \mathrm{~W}$ lightweight solar panel and a $3.3 \mathrm{~kW}$ electric motor. The simulation was performed based on meteorological data. An internal combustion engine analogous to the one installed on the boat emits on average $3 \mathrm{~kg} \cdot \mathrm{h}^{-1} \mathrm{CO}_{2}$, yet the solar boat produces no such emissions [22].

Traditionally, solar-powered mobile vehicles and watercraft are used effectively in areas where the sun is high above the horizon, i.e. the latitude is less than 55 degrees. Solar-powered boats are used and researched mostly in countries located closer to the equator. The sun shines on average only 90-110 days a year in Latvia. The aim of the research is to experimentally examine the possibilities of using a solarpowered boat with the sun being above the horizon at 21-48.7 degrees.

The experiments will be performed at the typical Latvian sun height period from August 10 to September 20 from 10 a.m. to 5 p.m. During the period from May 10 to August 10, the sun is higher on the horizon and hypothetically the use of a solar boat due to lack of energy should not be a problem.

\section{Materials and methods}

Technologies for watercraft to easily replace internal combustion engines with alternative energypowered motors are sought for in the world. Wind power and sailing boats have been used for centuries, yet it could be difficult for a daily user to drive a sailing boat on narrow rivers and canals, as well as in shallow waters. Therefore, the present research conducted an experiment on a fishing boat "Lidaka" (Pike) equipped with a standard Minn Kota Endura 30 electric motor.

The first test drive series was done on 11 August 2020 on the route Jelgava-Kalnciems-Jelgava. The experiment was conducted from 10.00 to 17.20. The first test drive was done as the solar boat preliminary functionally test for higher mileage without recharging the battery. The length of the route was $20.75 \mathrm{~km}$ one way. The average wind speed during the experiment was $2-4 \mathrm{~m} \cdot \mathrm{s}^{-1}$. At the beginning of the experiment, there was a headwind, yet on the way back there was a tailwind. A small-capacity lead-acid battery with a capacity of 5.0 Ah and a current of 20A in discharge mode was intentionally installed on the boat for the experiment. One boat operator participated in the experiment. The experimental route is shown in Figure 1.

a)

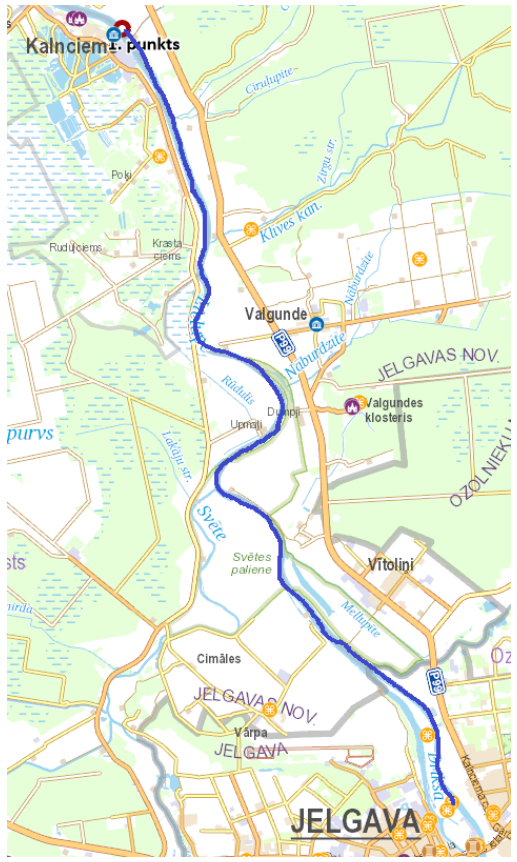

b)

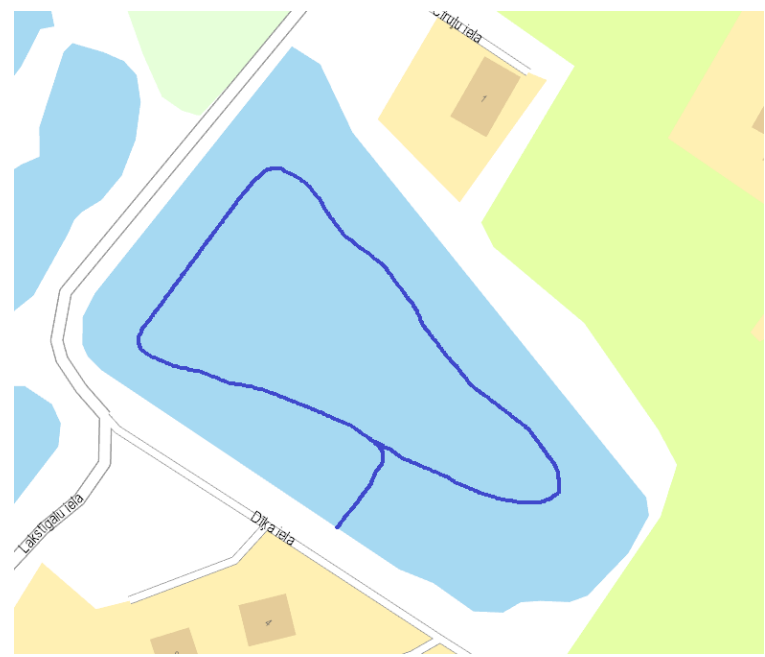

Fig. 1. Experimental route Jelgava-Kalnciems-Jelgava (on the Lielupe River, $41.5 \mathrm{~km}$ ) (a), experimental circle route (on a pond in Karnini village, N56 ${ }^{\circ} 41^{\prime} 06.88$ ", E23 47 '10.33" 0.34 km) (b) 
The experimental watercraft was a fiberglass boat "Lidaka". The boat was $5.5 \mathrm{~m}$ long and $1.1 \mathrm{~m}$ wide. An attaching bracket for the motor was mounted on the boat. The experiment used a Minn Kota Endura 30 electric motor. The motor had 5 power levels for forward movement and 3 power levels for reverse movement. The rated operating voltage of the motor was $12 \mathrm{~V}$, and the maximum current was up to 25A. A 330W 36V solar panel Canadian Solar CS1H-330MS was mounted on the front of the boat (Fig. 2).

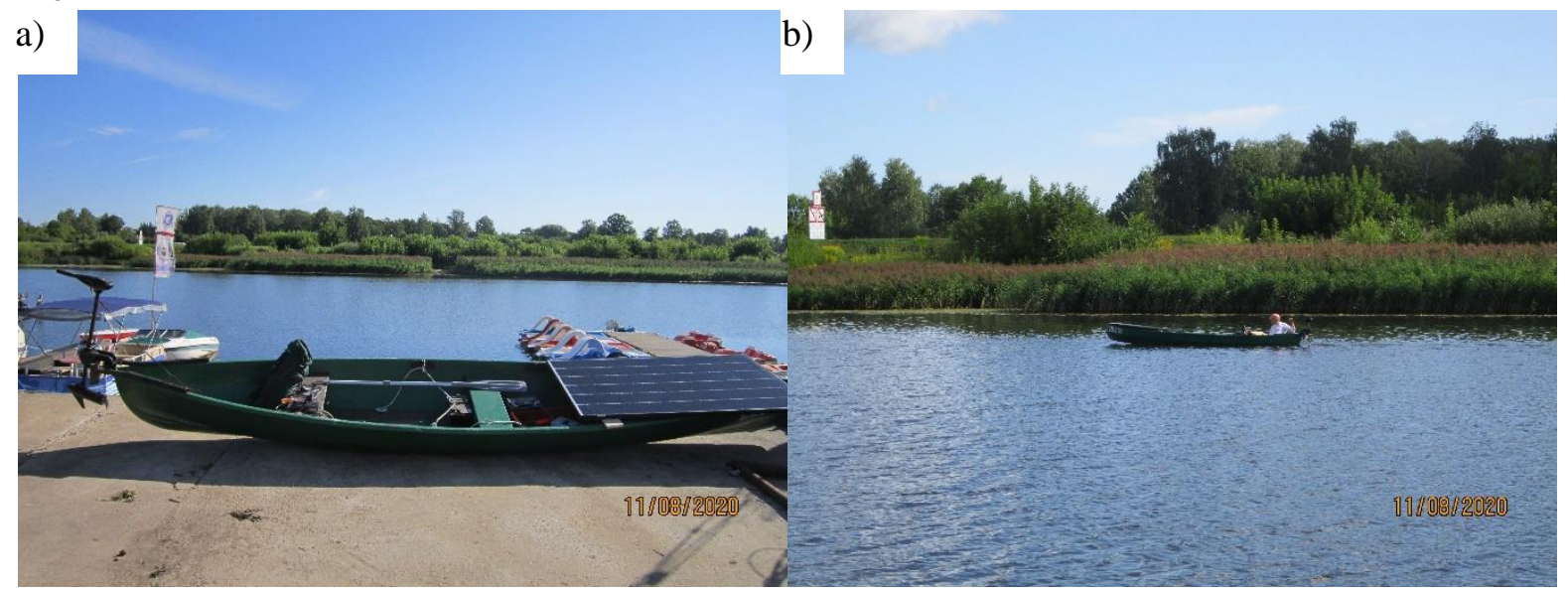

Fig. 2. Boat is prepared for experimental research (a); boat during the experiments (b)

The main technical parameters of the solar panel are summarized in Table 1.

Main technical parameters of solar panel Canadian Solar CS1H-330MS

Table 1

\begin{tabular}{|l|l|}
\hline \multicolumn{1}{|c|}{ Parameter } & \multicolumn{1}{c|}{ Parameter value } \\
\hline Maximum power & $330 \mathrm{~W}$ \\
\hline Optimum Operating Voltage & $36 \mathrm{~V}$ \\
\hline Optimum Operating current & $9.19 \mathrm{~A}$ \\
\hline Open Circuit Voltage & $43.5 \mathrm{~V}$ \\
\hline Maximum System Voltage & $1000 \mathrm{~V}$ \\
\hline Maximum Series Fuse Rating & $25 \mathrm{~A}$ \\
\hline
\end{tabular}

A logger HOLUX GP Sport 245 was used to store the route data and visually control the speed. The logger could operate in a temperature range from $-10 \mathrm{C}$ to $+50 \mathrm{C}$. The logger could store 200000 waypoints, measure speed, time, distance and store the route data.

A controller MPPT Epever Solar Charger 12/24/36V/48 V, 40A was used to control the energy flow to the battery and the electric motor. The main parameters of the controller are summarized in Table 2. During the experiment, the controller operated in $36 \mathrm{~V}$ input voltage mode and $12 \mathrm{~V}$ output voltage mode. The controller automatically determined the voltage of the connected solar panel and the voltage of the connected battery.

Table 2

Solar controller parameters

\begin{tabular}{|l|l|}
\hline \multicolumn{1}{|c|}{ Parameter } & \multicolumn{1}{c|}{ Parameter value } \\
\hline Operational temperature $\left({ }^{\circ} \mathrm{C}\right)$ & -25 to $+50{ }^{\circ} \mathrm{C}$ \\
\hline Max. power $(\mathrm{W})$ & 2080 \\
\hline Weight $(\mathrm{kg})$ & 2.47 \\
\hline Max output current (A) & 40 \\
\hline Nominal Voltage (V) & $12,24,36,48$ \\
\hline Max. input voltage (V) & 150 \\
\hline
\end{tabular}

For data recording, the experiment used a data logger Graphtech midi Logger GL220 with the following main parameters: the sampling interval ranging from $10 \mathrm{~ms}$ to $24 \mathrm{~h}$ and a time scale from $1 \mathrm{~s}$ 
to $24 \mathrm{~h}$. The device was equipped with a 4.3 -inch LCD display. The input voltage for the device was 8.5-24 V, while the number of measurement input channels was 10.

During the first performance test, the results stored by the logger will not be analyzed due to the large amount of data and various changes in motion conditions and resistance.

The second test drive series was carried out in standing water on a closed circle route. This series of test drives was carried out on 16 September 2020 from 12.50 to 17.10. The average length of the experimental circle route was 340 meters. The closed circle route was chosen with the intention that solar radiation is available from all sides while taking one measurement. In this way, the real operating conditions were simulated. The test drive lasted for at least 400 seconds. The experiment was done by one operator, who steered the boat and switched on or off the data logger. The data were logged 5 times per second. Solar radiation measurements were not recorded in the experiment.

After the experiment, the data on an exact 300-second drive were selected for processing, because the test drive data were already of high quality. The experiment performed measurements of battery and motor voltages and currents. Both the instantaneous power and the total power achieved during the experiment were calculated based on these parameters. The effect of the solar panel or the energy generated was calculated based on the energy balance of the motor and the battery according to the equation:

$$
P_{P V}=P_{B a t}+P_{M o t},
$$

where $P_{B a t}-$ instantaneous charging or discharging power of a battery, $\mathrm{W}$;

$P_{M o t}-$ instantaneous motor power consumption, W.

The measurements were made at all the 5 speed settings. Each measurement was repeated four times. From the obtained readings, the experiment used the readings of three replications with the most coherent data and calculated the average experimental values.

The experimental circuit diagram is shown in Figure 3. Shunt resistor outputs were calibrated using a Fluke 287 multimeter.

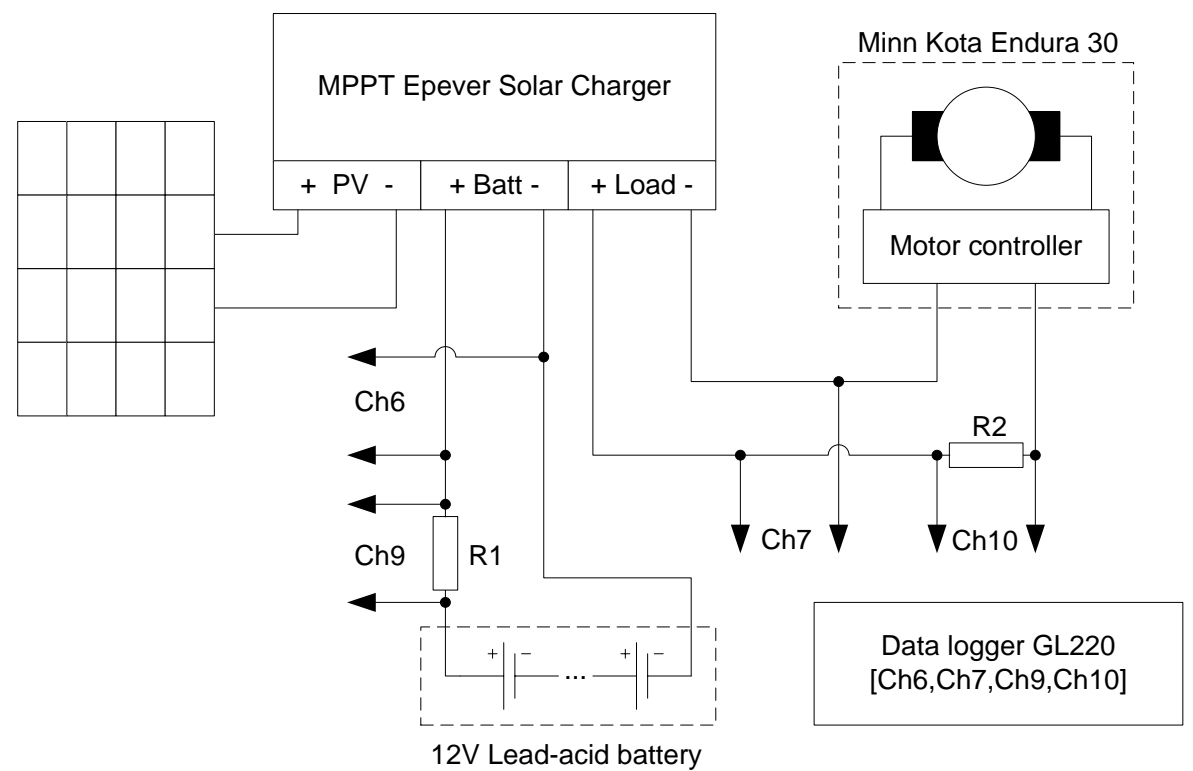

Fig. 3. Power and measurement circuit: $\mathrm{R} 1$ - shunt resistor $\left(1.012 \mathrm{mV} \cdot \mathrm{A}^{-1}\right) ; \mathrm{R} 2$ - shunt resistor $\left(1.503 \mathrm{mV} \cdot \mathrm{A}^{-1}\right)$; Ch6, Ch7, Ch9, Ch10 - signals to the GL220 data logger

\section{Results and discussion}

After the experiments, data processing was performed, and the data stored by the data logger were analysed. The voltage on battery terminals and charging and discharging currents, the motor voltage and the current consumed by the motor were logged during the experiments. The primary logged results obtained in the experiments are shown in Figure 4. 
During the experiments at speed setting 5, the average motor current was $20.07 \mathrm{~A}$, the maximum current reached $21.86 \mathrm{~A}$, while the minimum current was 19.24 A (Fig. 4). No significant current changes were observed in smooth movement, while small current changes could be explained by small changes in motion resistance during turns. The change in battery output current ranged from 8.27 to 12.13 A, while the average current was $9.04 \mathrm{~A}$. The lowest readings of battery output current were observed, when the solar panel was at the best angle to solar radiation, and the solar panel was able to produce the most energy, yet the highest readings were observed, when the solar panel generated the least energy. The power calculation results for speed settings 1-5 are shown in Figure 5- 9.

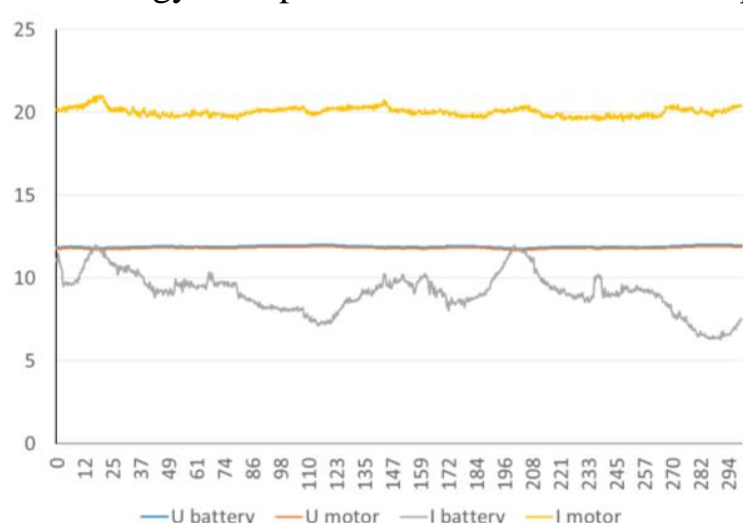

Fig. 4. Sample of logged data

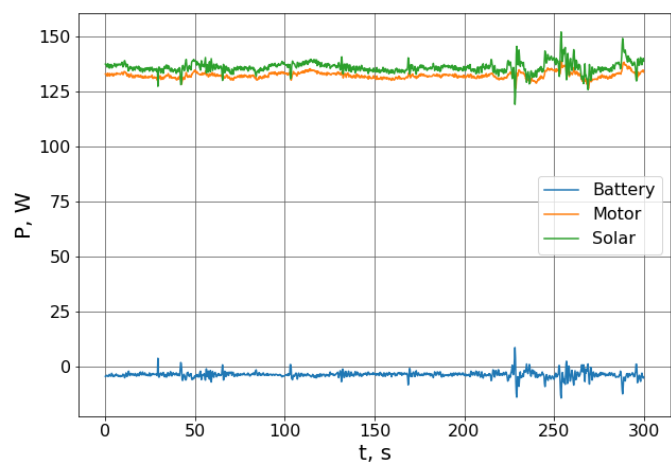

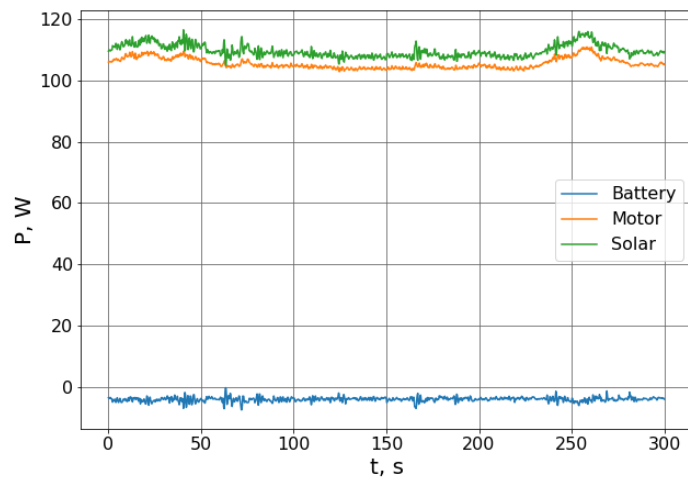

Fig. 5. Calculated power, speed setting 1, run 3

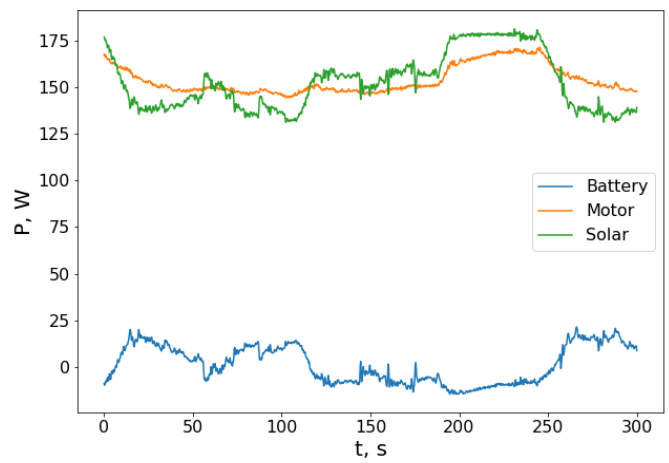

Fig. 6. Calculated power, speed setting 2, run 2 Fig. 7. Calculated power, speed setting 3, run 3
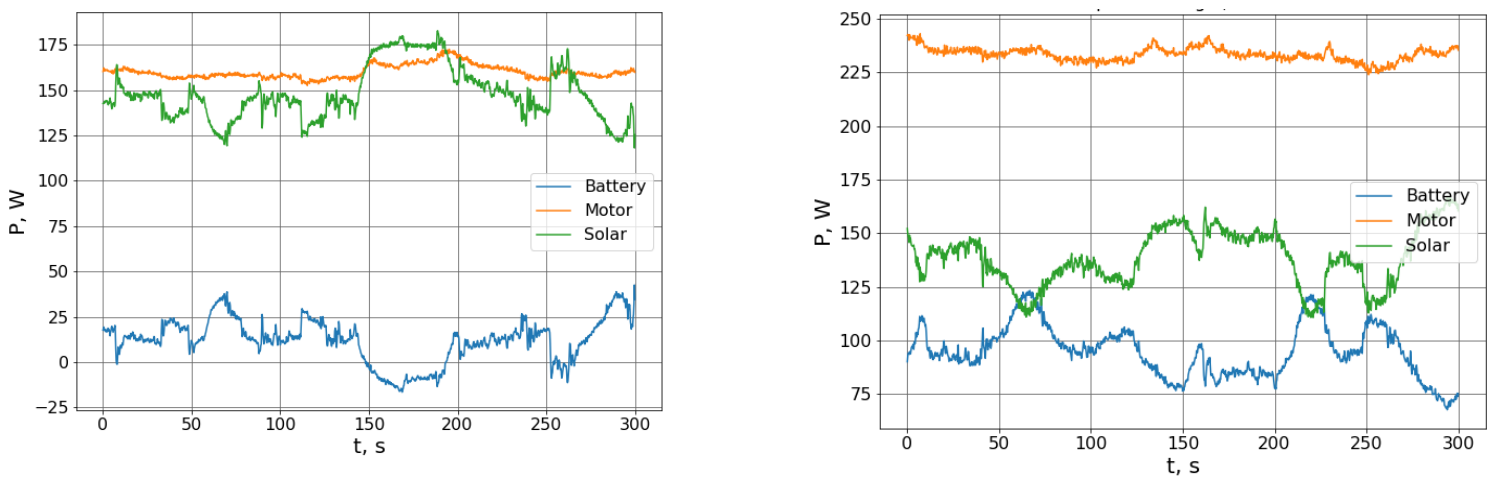

Fig. 8. Calculated power, speed setting 4, run 3 Fig. 9. Calculated power, speed setting 5, run 3

In the power graphs, negative readings for the battery indicated its charging capacity and positive readings showed its discharging capacity. In all the graphs, the power of the solar panel and the power of the motor had positive readings, which indicated that the solar battery generated the necessary power to charge the battery and run the motor, while the motor consumed the power generated. At speed setting 1 , the battery charging capacity varied from 0.3 to $7.5 \mathrm{~W}$ (Fig. 5). The solar panel was able to move the boat and charge the battery. The power of the motor ranged from $102.9 \mathrm{~W}$ to $110.9 \mathrm{~W}$ due to load changes in turns and other insignificant load changes. The highest power consumption and solar panel 
power output was reached at the $257^{\text {th }}$ second of the experiment. At speed setting 2 , the maximum discharging capacity of the battery, $8.6 \mathrm{~W}$, was observed at the $228^{\text {th }}$ second (Fig. 6). At that moment, the solar panel power output was the lowest, $119 \mathrm{~W}$, which could be explained by a small cloud reducing solar radiation. Even at this speed setting the solar panel fully supplied the power output required for moving the boat.

In the 3rd gear, the power output of the solar cell up to 115 seconds of the experiment was practically less than the motor power and ranges from 132 to $156 \mathrm{~W}$ (Fig. 7). In the next stage of the experiment, up to 253 seconds, the solar cell was in the range of 152 to $180 \mathrm{~W}$, but the motor power was in the range of 152 to $170 \mathrm{~W}$. There was also a tendency that as the solar intensity increase, the voltage supplied to the motor increase, increasing the motor power. At the end of the experiment, the power of the solar battery dropped again, when the power needs compensated from the battery in the range of 18-20 W.

At speed setting 4, the maximum discharging capacity of the battery was $42 \mathrm{~W}$, while the charging capacity reached $16 \mathrm{~W}$ (Fig. 8). The charging time during the experiment was only 55 seconds. During the battery charging, the solar panel power output exceeded the power consumed by the motor, reaching an average of 175-180 W. The changes in motor power in this mode during the whole experiment were relatively small - in the range of 152-172 $\mathrm{W}$. The maximum power of the motor was achieved during the period when the solar panel was able to supply the required power output to the motor. Based on this trend, we can conclude that by means of a solar panel it is possible to achieve a higher speed than if using only a battery. At speed setting 4, the power consumed from the battery at moments when the solar panel was not able to generate the required amount of energy tended to increase.

At speed setting 5, the power consumed by the motor was in the range of 223 to $243 \mathrm{~W}$ (Fig. 9). The solar panel in Latvia was able to provide such a power output only when the sun was high above the horizon because the solar panel was placed at a fixed angle and almost horizontally. The power output of the solar panel ranged from $116 \mathrm{~W}$ to $167 \mathrm{~W}$, while the rest of the power was provided by the battery. Just like at the other speed settings, the motor power curves showed no significant and rapid changes. A very pronounced trend was observed during the 130-210 seconds of the experiment, when solar power reached the maximum, and there was also an increase in the power consumed by the motor. At this stage, there was also a decrease in the battery discharging capacity by on average $50 \%$.

The average amounts of energy for the motor, the solar panel and the battery logged during all experimental replications are summarized in Figure 10.

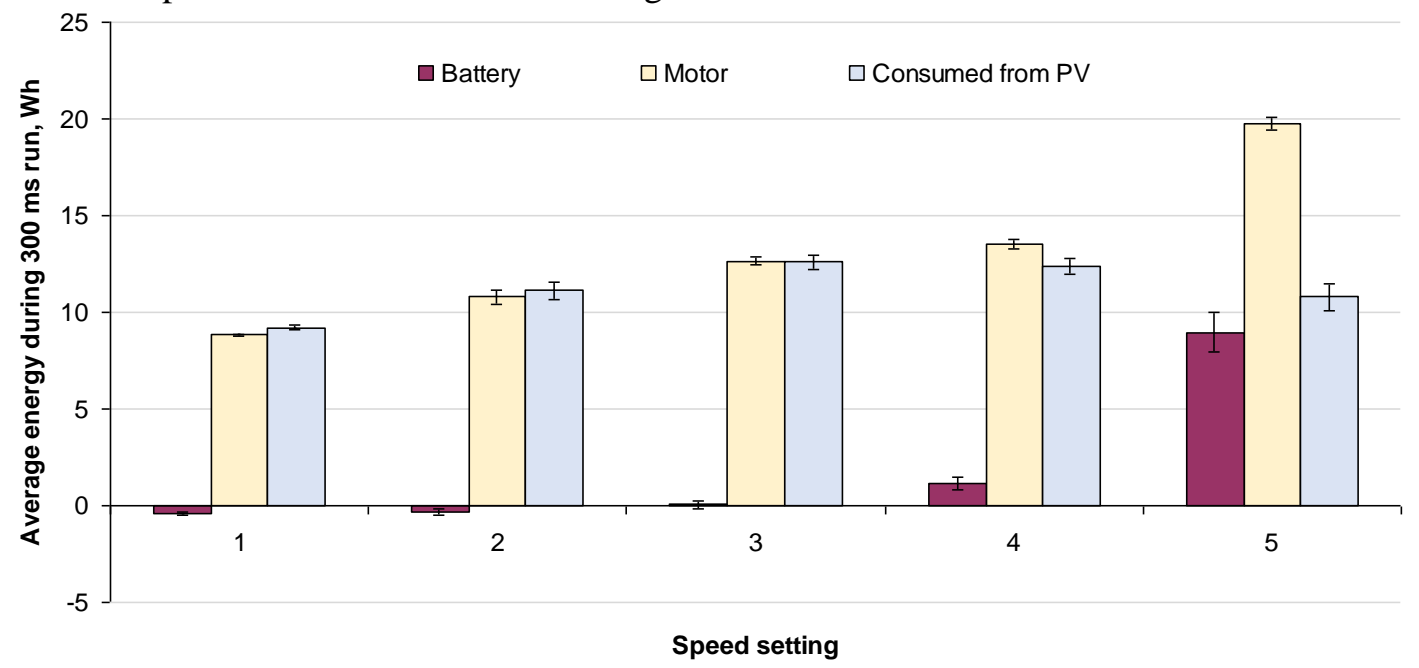

\section{Fig. 10. Average energy for various components during all test drives at given speed settings;} error bars show standard deviation

One of the most important indicators is the amount of energy consumed by the motor, which shows the potential possibility to run the motor only on solar power at a certain speed setting power. At speed setting 1 , the energy consumed by the motor was $8.81 \mathrm{Wh}$, while at speed setting 2 , the increase was small, $10.8 \mathrm{Wh}$, or an increase of $22.6 \%$. The increases at speed settings 3 and 4 were also relatively small, $17.2 \%$ and $6.6 \%$ (12.66 $\mathrm{Wh}$ at speed setting 3 and $13.50 \mathrm{Wh}$ at speed setting 4 , respectively) compared with the previous speed setting. The situation changed significantly at speed setting 5 , as the 
electricity consumption increased by $46.4 \%$ compared with speed setting 4 . Therefore, if operating such a watercraft, significant attention should be paid to the choice of a speed setting, because if operating it at speed setting 5, the average speed was $6.6-7.0 \mathrm{kmh}^{-1}$, while at speed setting 4 it was $5.6-6.0 \mathrm{kmh}^{-1}$ (speed decreased only by $16 \%$ ). The increase in power is associated with an the increase in the resistance of water, as the speed of movement increases.

At the first three speed settings, the solar panel was able to fully provide the motor with solar power, while at speed setting 4 an energy deficit of $8.5 \%$ was offset by the battery $(1.15 \mathrm{Wh})$. At speed setting 5 , solar power was able to provide about half of the required amount of energy for the boat, and the remaining $45.3 \%$ was provided by the battery. It should be noted that the experiment was performed at a latitude above 56 degrees in September, when the sun did not rise above 36 degrees above the horizon at noon. To make better use of solar power, it is necessary to use a solar tracking system, especially in cases, in which the watercraft is planned to travel on a constant course for a long time.

\section{Conclusions}

1. A working prototype of a solar-powered boat was developed. In the pilot experiment, the boat travelled $41.5 \mathrm{~km}$ on a sunny day on 11 August at coordinates 56.038' N E23.042', when the maximum angle of the sun above the horizon was 48.69 degrees.

2. During the pilot experiment, the solar panel, depending on the height of the sun above the horizon (specific hours of the day), ran the watercraft at speed settings 4 and 5 without discharging the battery for $8.5 \mathrm{~h}$.

3. During the test drives carried out on 16 September 2020 on a closed circle route in standing water, the height of the sun above the horizon did not exceed 36 degrees, which affected the amount of the energy generated. The movement of the boat without discharging the battery was only possible at the first three speed settings.

4. The curves recorded during the experiments allow us to estimate the efficiency of the solar panel and the degree of solar power used, which varied, depending on the height of the sun above the horizon. For the next stages of the research, it is recommended to develop an automatic solar tracking system for a boat traveling on a little variable course, which could increase the efficiency of solar power.

5. For safe operation of a solar-powered boat, it is necessary to develop a simple current and voltage measuring device for the battery in order to be able to control the discharge or charge of the battery, depending on a speed setting and the height of the sun above the horizon.

6. The amounts of energy consumed by the boat at various speed settings in the experiments were as follows: $8.81 \mathrm{Wh}$ at speed setting $1,10.80 \mathrm{Wh}$ at speed setting $2,12.66 \mathrm{Wh}$ at speed setting $3,13.50$ Wh at speed setting 4 and $19.76 \mathrm{Wh}$ at speed setting 5. At speed setting 5, 45.3\% more energy was required than that at speed setting 4 , while the speed increased only by $16 \%$ due to an increase in water resistance at higher speeds.

7. For safe operation of a solar boat in sunny weather, it is useful to equip the boat with a battery with an at least 3-fold lower capacity - $30 \mathrm{Ah}$ - than in the case of a traditional boat having no solar panel.

8. Due to the ability of the solar panel to generate a slightly higher operating voltage than the battery provided, the motor operated at a higher speed and the boat speed also increased.

9. Under the conditions in Latvia, the highest efficiency of a solar-powered boat could be achieved from April to September; however, in sunny weather, electricity generation is possible in other months of the year. A solar panel is convenient for automatically charging the battery and maintaining it in a charged state while the boat is in port.

\section{References}

[1] The automobile industry pocket guide. European manufacturers association. 2019/2020. 82 p.

[2] Osadcuks V., Pecka A., Selegovskis R. Energetic balance of autonomous hybrid renewable energy based EV charging station in winter condition. Agronomy Research, 11 (2), 2013, pp. 357-366.

[3] Berjoza, D.\& Misjuro, E. 2014. Use of solar energy in small capacity electric vehicles. Proceedings of the 13th International scientific conference „Engineering for rural development.” Latvia 
University of Agriculture. Faculty of Engineering. Jelgava. Vol.13, pp.312-317. [online] [15.02.2021] Available at http://tf.llu.lv/conference/proceedings2014/Papers/53_Berjoza_D1.pdf

[4] Nasirudin A., Chao R.M., Utama K. A. P. Solar Powered Boat Design Optimization. Proceeding of 10th International Conference on Marine Technology, Procedia Engineering 194, 2017, pp. 260 - 267

[5] Reid R.L., Hoeppner B. D. Five years of solar powered boat racing at Marquette University. Annual Conference, June 15-18, 1997, Milwaukee, Wisconsin, pp. 2.201 .1 - 2.201.14.

[6] Gorter T. Design consideration of a solar racing boat: propeller design parameters as a result of PV system power. Proceeding of the $7^{\text {th }}$ International Conference on Applied Energy - ICAE2015, Energy Procedia 75, 2015, pp.1901-1906.

[7] Schouten T. N. Stability analysis of the equations of motion for the 2014 Delft Solar Boat. Technische Universiteit Delft, Netherland, 2015, 52 p.

[8] Rivera-Solorio C., Garcia'A-Cue'Llar A., Flores A. Design and construction of a boat powered by solar energy with the aid of computational tools. International Journal of Engineering Education, vol. 29, No. 2, 2013, pp. 380-387

[9] Nobrega J. C., Rosling A. Development of solar powered boat for maximum energy efficiency. International conference on Renewable Energies and Power Quality, March 28-30, 2012, Santiago de Compostela, Spain, pp. 302-307.

[10] Mahmud K., Morsalin S., Khan Md. I. Design and fabrication of an automated solar boat. International Journal of Advanced Science and Technology, vol.64, 2014, pp.31-42.

[11] Kurjakov A., Kurjakov M., Miskovic D., Caric M. Electrical characteristics of thin film solar panels on a river boat under different microclimatic conditions. Facta Universitatis, Elec. Energ., vol 25, Nr. 2, August 2021, pp.151-160.

[12] Kurniawan A. A review of solar-powered boat development. IPTEK, The journal for Technology and Science, vol.27, No.1, April 2016, pp.1-8.

[13] Sutherlanda J., Saladob A., Oizumia K., Aoyamaa K. Implementing value-driven design in modelica for a racing solar boat. Proceeding of the 15th annual conference on Systems Engineering Research Disciplinary Convergence: Implications for Systems Engineering Research. March 2325, 2017, California, USA

[14] Das S., Sadhu P.K., Chakraborty S., Pal N., Majumdar G. New generation solar PV powered sailing boat using boost chopper. TELKOMNIKA Indonesian Journal of Electrical Engineering, vol.12, No.12, December 2014, pp. 8077-8084.

[15] Das S., Pradip Kumar Sadhu P. K., Pal N., Majumdar G., Mukherjee S. Solar photovoltaic powered sailing boat using buck converter. International Journal of Power Electronics and Drive System (IJPEDS), vol. 6, No. 1, March 2015, pp. 129-136.

[16] Leiner R. Research solar power boat - data management and online visualization. IEEE, AFRICON 2007, Sept. 26-28, 2007, Windhoek, South Africa [online] [15.02.2021.]. Available at: https://ieeexplore.ieee.org/document/4401548?arnumber $=4401548$

[17] Banjarnahor D. A., Hanifan M., E M Budi E. M. Design of hybrid solar and wind energy harvester for fishing boat. International Conference on Green and Renewable Energy Resources: Earth and Environmental Science, vol. 75, 2017

[18] Tukaram S. D., Uttam S. R., Shivaji R. S., Ankush N. R. Design and fabrication of a solar boat model. International Journal of Scientific Research in Science: Engineering and Technology, 2016, vol. 2, issue 2, pp. 644-646.

[19] Sunaryo S., Ramadhani A. W. Electrical system design of solar powered electrical recreational boat for Indonesian waters. E3S Web of Conferences, vol. 67, 2018

[20] Lutful Kabir S. M., Alam I., M. Rezwan Khan M., Hossain M. S., Rahman K. S., Amin N. Solar powered ferry boat for the rural area of Bangladesh. International Conference on Advances in Electrical, Electronic and System Engineering, Nov. 14-16, 2016, Putrajaya, Malaysia

[21] Spagnolo G. S., Papalillo D., Martocchia A., Makary G. Solar-electric boat. Journal of Transportation Technologies, vol. 2, 2012, pp. 144-149.

[22] Kapuscik W., Maraszek J., Borowicz M., Sornek K. AGH solar boat - the analysis of energy and ecological parameters of the solar powered boat. 2nd International Conference on the Sustainable Energy and Environmental Development: Earth and Environmental Science, vol. 214, 2019. 